Vol.: 5 Issue: 2 Date: 31.12.2021 Received: 02.11.2021 Accepted: 15.12.2021 Final Version: 31.12.2021

ISVOS Journal, 2021, 5(2): 192-199 - https://doi.org/10.47897/bilmes.1017882

\title{
Relationship Between Metals In Ovacık Stream Sediment Samples
}

\author{
Güllü KIRAT ${ }^{\mathrm{a}, 1}$ \\ ${ }^{a, 1}$ Department of Geological Engineering, Faculty of Architecture and Eng. Yozgat Bozok University, Yozgat, Turkey \\ ORCID ID: 0000-0002-5859-9592
}

\begin{abstract}
Ovacık Village is located in Balıkesir province and is $12 \mathrm{~km}$ away from Balıkesir Center. The GPS coordinates of Ovacık Village are 39 43' 51" North and $27^{\circ} 47^{\prime} 37^{\prime \prime}$ East. The stream sediments in the study area consisted of the erosion of magmatic, metamorphic and volcanic rocks and surface waters and eroded rock particles along the stream bed. The relationship between metals in stream sediments has been investigated on the basis of geochemical properties. As, $\mathrm{Cd}, \mathrm{Cu}, \mathrm{Mn}, \mathrm{Ni}, \mathrm{Pb}$ and $\mathrm{Zn}$ element contents of 23 stream sediment samples were taken from different locations from Ovacik village and its surroundings. The minimum, maximum, medyan, median and standard deviation values of these metals in the stream sediments were calculated and it was observed that the mean values were higher than the standard deviation values. The minimum and maximum values (ppm) of the metals studied As: 7.7 - 51.3, Cd: 0.13 - 0.58, Cu: 25.2 - 70.6, Mn: 661 - 1135, Ni: 8.6 - 33.7, Pb: 12.3 - 57.7 and Zn: 59 - 220 According to the Spearman correlation coefficient values, a strong positive correlation was observed between $\mathrm{As}-\mathrm{Cu}, \mathrm{Cd}-\mathrm{Pb}$, $\mathrm{Cd}-\mathrm{Zn}, \mathrm{Cu}-\mathrm{Ni}$ and $\mathrm{Pb}-\mathrm{Zn}$ metal associations $(\mathrm{p}<0.01)$. Factor analysis was made with the obtained analysis results and 3 different factor values were created and analyzed. Factor $1: \mathrm{Cd}-\mathrm{Pb}-\mathrm{Zn}$ association and $37.01 \%$ of the total variance; Factor $2: \mathrm{Cu}-\mathrm{Mn}-\mathrm{Ni}$ association and $24.7 \%$ of the total variance; Factor 3: As and total variance was $18.4 \%$, the total variance value was found to be $80.1 \%$. The spatial distributions of the metals were analyzed using the Surfer 9.0 program in the creation of the distribution maps. As and $\mathrm{Cu}$ elements at locations 16 and $17 ; \mathrm{Mn}$ and $\mathrm{Ni}$ elements at locations 3,6 and 7; $\mathrm{Cd}, \mathrm{Pb}$ and $\mathrm{Zn}$ elements have the highest values in locations 3,12 and 20, they show a similar distribution.
\end{abstract}

Keywords: "Stream Sediment, Spearman Correlation, Variance Value, Mean Value, Standard Deviation"

\section{Giriş}

Akarsu sedimanları genellikle bölgesel jeokimyasal araştırmalar için bir keşif aracı olarak kullanılmaktadır [1, 2]. Aktif akarsu çökeltileri ince - orta taneli katı malzemeyi (killi-siltli-kumlu) temsil eder ve akarsu veya nehir suyu ile aşınmış kayaçların ve toprağın erozyonundan oluşan parçacıklar akıntıya bağlı olarak dere yatağı boyunca sürünerek taşınır. Bu nedenle, dere drenaj ağının kaynak havza alanını temsil eder $[3,4]$.

Nehirlerdeki akarsu çökeltisinin mineralojisi, parçacık boyutu ve jeokimyasını, kaynak kayaçların bileşimini, fiziksel ve kimyasal ayrışmayı, havzanın hidrolojik ve morfolojik özelliklerini ve iklim özelliklerini yansıtmaktadır [4, 5, 6, 7, 8].

Jeokimyasal ve mineralojik özelliklerin, akarsu sedimanlarının partikül boyutu dağılımı üzerindeki etkisi önemlidir [4, 9].

Birçok araştırma sonucu, tortunun kimyasal bileşiminin, aşağıdakilerden dolayı tane boyutuna göre değiştiğini ortaya koymaktadir:

- mineralojik ve dokusal olarak farklı tane boyutlarına katkıda bulunan çok sayıda kaynak;

- kaya parçalarının mekanik olarak daha ince bileşenlere ayrılması;

- zayıf tanelerin kimyasal olarak bozunma ürünlerine dönüşmesi.

Bir akarsu tortusu örneğindeki boyut fraksiyonlarının incelenmesi, farklı jeolojik süreçleri tanımlamak için kullanılır. Bir bölgenin jeokimyasının nasıl yorumlanabileceği üzerinde büyük bir etkiye sahip olabilirler [4, 6].

\footnotetext{
${ }^{1}$ Corresponding author. Tel.: 03542421001

E-mail: gullu.kirat@yobu.edu.tr
} 
Akarsu sedimanları, magmatik, tortul ve volkanik kökenli kayaçların aşınmasından kaynaklanır. Bunlardan bazıları kolayca aşınırken, bazıları ise özellikle kristal ve metamorfik kayaçların yalnızca yüzey katmanları akıntıdan etkilenirler. Ağır minerallerin magmatik, metamorfik ve tortul kayaçlarda oluştuğu bilinmektedir. Bu mineraller yüksek özgül ağırlığa sahiptir ve yeterli büyüklükte konsantrasyonlarda ve yeterince büyük boyuttaki birikintilerde meydana gelirlerse ekonomik olarak değerlidirler. Akarsu sedimanları da kısa bir süre içinde büyük ölçekli tarımsal faaliyetlerden etkilenir [10].

Çalışma alanı ve çevresindeki dere sediment örnekleri istatistiksel olarak analiz edilerek jeokimyasal özellikleri belirlenmeye çalışılmıştır. $\mathrm{Bu}$ çalışmada, $\mathrm{As}, \mathrm{Cd}, \mathrm{Cu}, \mathrm{Mn}, \mathrm{Ni}, \mathrm{Pb}$ ve $\mathrm{Zn}$ elementlerinin korelasyon değerleri, faktör değerleri ve alansal dağılımları incelenerek ve dere sedimentlerindeki ağır metal kirliliği ve çevreye etkisi incelenmeye çalışılmıştır.

\section{Jeoloji}

Ovacık Köyü Balıkesir ilinde yer almakta olup, Balıkesir Merkez Köyleri semtinde bulunan Ovacık Köyü Balıkesir Merkez ilçesine bağlıdır. Ovacık Köyü haritası konumu ise 39 43' 51" Kuzey ve 27 47' 37" Doğu koordinatlarıdır. Ovacık Köyü bağlı olduğu Balıkesir Merkez ilçe merkezine 12 kilometre mesafe uzaklıktadır (Şekil 1). Tarımsal ekonominin merkezinde olup oldukça işlek yolların kavşağında yer alan bir ulaşım merkezidir.

Tersiyer yaşlı volkanik kayaçlar, Türkiye'nin kuzeybatısındaki birçok hidrotermal Au yataklarını içermektedir [11]. Epithermal $\mathrm{Au}( \pm \mathrm{Ag})$ yatakları volkanik, tortul ve metamorfik kayaçların üzerinde yer almaktadır. Cevher mineralleri çoğunlukla Au ve Ag gibi değerli metallerdir ancak bazı epitermal yataklarda $\mathrm{Cu}, \mathrm{Pb}$ ve $\mathrm{Zn}$ gibi baz metaller de bulunmaktadır [12].

Altın cevherleşmesi, dünyada çoğunlukla yapısal olarak kontrol edilebilir çatlak, makaslama kırıklarında ve faylanmalarla ilişkilidir. Çalışma alanı ve çevresi Hallaçlar Volkanikleri içerisinde yer almaktadır (Şekil 2). Hallaçlar volkanik kayaçları Üst Oligosen-Erken Miyosen yaşlıdır [13]. Bu kayaçlarda zamanla değişime uğramıştır ve ana alterasyon zonları silisleşme ve kaolinleşme şeklindedir. Ayrıca çalışma alanında pirit mineralizasyonu da gözlenmektedir. Hallaçlar Formasyonu kırmızı, kahverengi, beyaz-kirli sarı renkte olup andezitik-dasitik ve silisleşmiş kayaçlar ve bunların alterasyon ürünlerinden oluşmuştur [14].

Hallaçlar Formasyonu'nun petrografik incelemesi sonucunda biyotit, hornblend, ojit ve kuvars içeren bir matriks ile biyotit mikrolitleri içeren volkanik camsı malzemeye sahip olduğu görülmüştür [15].

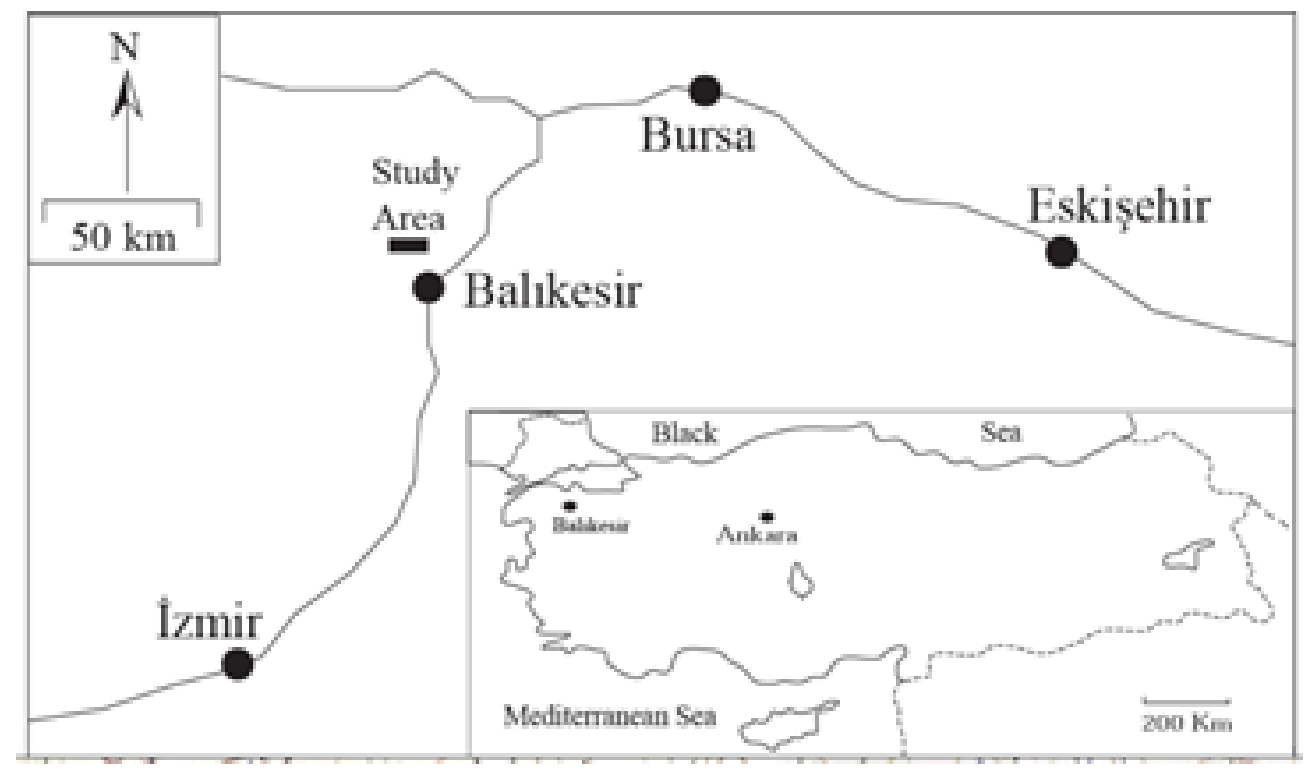

Şekil 1. Çalışma alanına ait yer bulduru haritası 


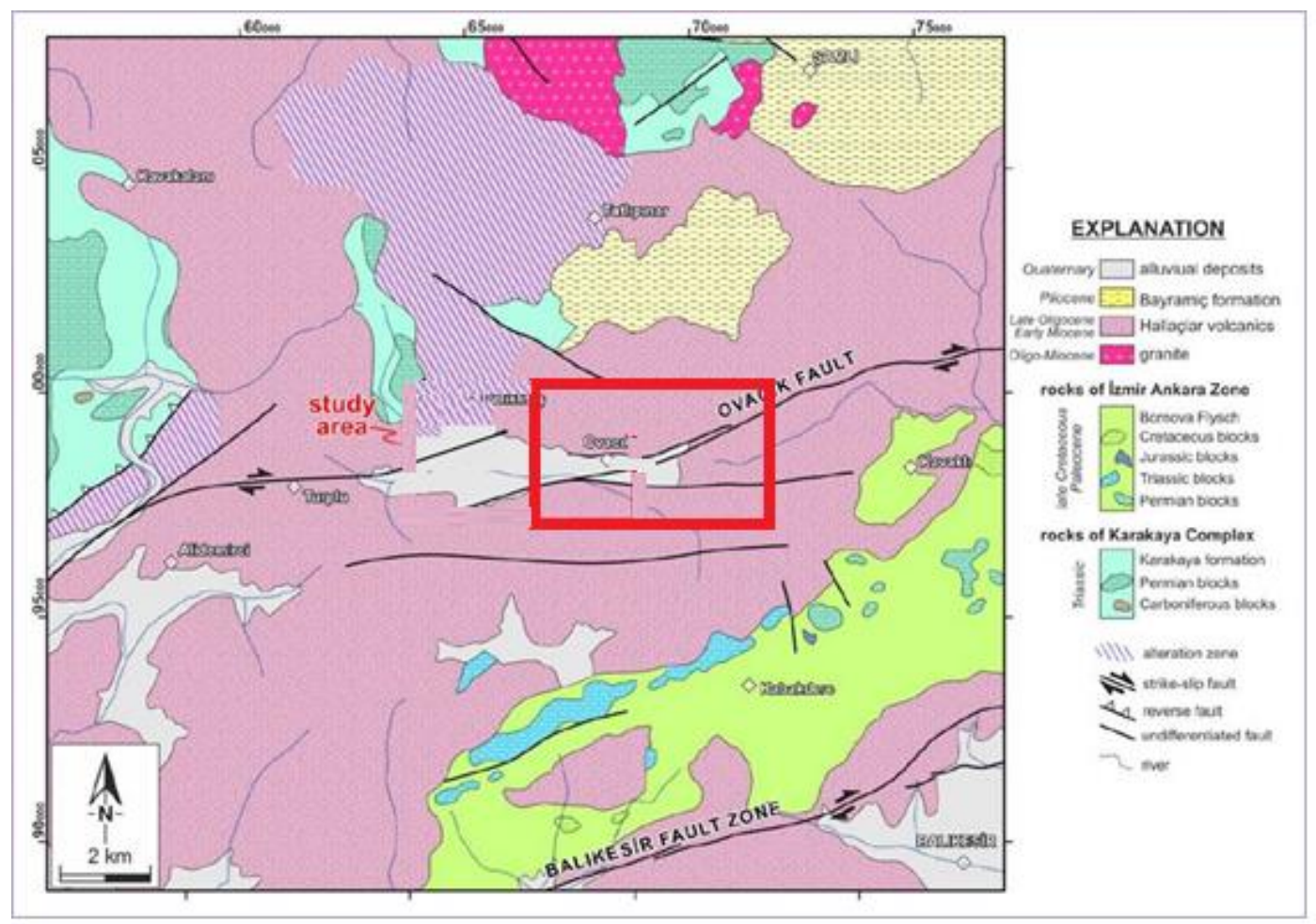

Şekil 2. Çalışma alanı Jeoloji Haritası [16]

\section{Materiyal ve Method}

Çalışma alanındaki dere yatağında örnekleme lokasyonları seçilmiş ve GPS ile 23 adet örnek alınmıştır. Her lokasyondan 0,5$1 \mathrm{~kg}$ ağırlığında alınan sediment örnekleri numaralandırılarak oda sıcaklığında kurutuldu. Tüm numuneler, $<2 \mathrm{~mm}$ açıklığa sahip paslanmaz çelik bir elek kullanılarak elendi.

Element analizleri (mikrodalga sistemde ekstraksiyondan sonra) Me-MS41 yöntemi ve ICP-MS (Endüktif Eşleşmiş PlazmaKütle Spektrometresi) cihazı kullanılarak yapılmıştır [17].

\section{Tartışma ve Sonuçlar}

İnceleme alanı ve yakın çevresinden alınan 23 adet dere sediment örneğinden elde edilen analiz sonuçları istatistiksel olarak değerlendirilmiştir. As, $\mathrm{Cd}, \mathrm{Cu}, \mathrm{Mn}, \mathrm{Ni}, \mathrm{Pb}$ ve $\mathrm{Zn}$ elementlerinin aritmetik ortalama değerlerinin standart sapma değerlerine göre daha yüksek olduğu görülmüştür.

Tablo 1. Çalışma alanı dere sedimentlerinin jeokimyasal veri setinin istatistiksel özeti $(n=23)$

\begin{tabular}{lrrrrrrr} 
& $\mathbf{A s}$ & $\mathbf{C d}$ & $\mathbf{C u}$ & $\mathbf{M n}$ & $\mathbf{N i}$ & $\mathbf{P b}$ & $\mathbf{Z n}$ \\
\hline $\mathbf{N}$ & 20 & 20 & 20 & 20 & 20 & 20 & 20 \\
A.Ortalama & 20.0 & 0.3 & 44.7 & 920.3 & 14.8 & 27.9 & 90.4 \\
Medyan & 16.75 & 0.2 & 42 & 951.5 & 13.95 & 22.45 & 83.5 \\
Std. Sapma & 10.6 & 0.1 & 11.6 & 143.1 & 5.7 & 13.5 & 33.5 \\
Aralık & 43.6 & 0.45 & 45.4 & 474 & 25.1 & 45.4 & 161 \\
Minimum & 7.7 & 0.13 & 25.2 & 661 & 8.6 & 12.3 & 59 \\
Maksimum & 51.3 & 0.58 & 70.6 & 1135 & 33.7 & 57.7 & 220 \\
\hline
\end{tabular}


İncelenen elementler arasında hesaplanan sperman korelasyon katsayılarına göre, $\mathrm{As}-\mathrm{Cu}, \mathrm{Cd}-\mathrm{Pb}, \mathrm{Cd}-\mathrm{Zn}, \mathrm{Cu}-\mathrm{Ni}, \mathrm{ve} \mathrm{Pb}-\mathrm{Zn}$ arasında yüksek pozitif bir korelasyon olduğu görülmüştür.

Tablo 2. Elde edilen elementler arası sperman korelasyon katsayıları

\begin{tabular}{|c|c|c|c|c|c|c|c|}
\hline & As & Cd & $\mathrm{Cu}$ & Mn & $\mathbf{N i}$ & $\mathbf{P b}$ & Zn \\
\hline As & 1 & & & & & & \\
\hline Cd & $-0,314$ & 1 & & & & & \\
\hline $\mathrm{Cu}$ & $.613(* *)$ & $-0,098$ & 1 & & & & \\
\hline Mn & 0,008 & $.496\left(^{*}\right)$ & 0,356 & 1 & & & \\
\hline $\mathbf{N i}$ & 0,331 & $-0,136$ & $.778(* *)$ & 0,177 & 1 & & \\
\hline $\mathbf{P b}$ & $-0,14$ & $.730(* *)$ & $-0,185$ & 0,315 & $-0,287$ & 1 & \\
\hline $\mathbf{Z n}$ & $-0,242$ & $.894(* *)$ & 0,028 & $.503(*)$ & 0,083 & $.703(* *)$ & 1 \\
\hline$* *$ & Correlation & ficant at & 1 level (2 & & & & \\
\hline$*$ & Correlation & iificant at & )5 level (2 & & & & \\
\hline
\end{tabular}

Korelasyon matrisinde bir değişkenin diğer bir değişken ile ilişkisi belirlenir. Faktör analizlerinin amacı, korelasyonları açılamak için faktörler elde etmektir. Korelasyon matrislerine bakılarak faktör sayısı belirlenebilir. Her bir değişken yüksek korelasyon gösteren değişken ile aynı grupta toplanır ve faktör oluşturulur [18].

Hesaplanan toplam varyansa göre, başlangıç özdeğerlerinin sütununun altında 1. sütunda tüm değişkenler, 2. sütunda değiş̧kenlerin özdeğerleri, 3. sütunda özdeğerlerin açıkladığı varyans yüzdeleri, 4. sütunda eklemeli varyans değerleri yer almaktadır.

Döndürme yapıldıktan sonra karesel yüklerin toplamı sütununda bulunan özdeğerlerde, varyans \% ve eklemeli varyans değerleri değişmiş̧ir. Fakat toplam eklemeli varyanslar değiş̧memiştir. Tablo 3 incelendiğinde 1 . faktör toplam varyansın yaklaşık $\%$ 37'sini açıklamaktadır. 2. faktör toplam varyansın yaklaşık \% 24'ünü 3.faktör ise toplam varyansın yaklaşık \% 18 'ini açılamaktadır. Bu varyans değerleri giderek azalmaktadır. Özdeğerleri 1'den büyük olan ilk 3 faktörün toplam varyansının açılama yüzdesi \% 80.083 olup oldukça yüksek bir değerdir.

Tablo 3. Çalışma alanı dere sedimaentlerinin $(n=23) 7$ element için üç faktörün açıklanan toplam varyansı

Bileşenler

As

Cd

$\mathrm{Cu}$

Mn

$\mathrm{Ni}$

$\mathbf{P b}$

$\mathrm{Zn}$
Başlangıç Özdeğerleri

Döndürme Yapıldıktan Sonra Karesel Yüklerin Toplamı

\begin{tabular}{lrrrrrl} 
& Toplam & Varyans \% & Kümülatif \% & Toplam & Varyans \% & Kümülatif \% \\
As & 2.607 & 37.238 & 37.238 & 2.591 & 37.011 & 37.011 \\
$\mathbf{C d}$ & 2.049 & 29.275 & 66.513 & 1.726 & 24.663 & 61.674 \\
$\mathbf{C u}$ & 0,95 & 13.570 & 80.083 & 1.289 & 18.410 & 80.083 \\
\hline $\mathbf{M n}$ & 0,631 & 9.014 & 89.097 & & & \\
$\mathbf{N i}$ & 0,387 & 5.530 & 94.627 & & & \\
$\mathbf{P b}$ & 0,236 & 3.373 & 98.000 & & & \\
$\mathbf{Z n}$ & 0,14 & 2.000 & 100.000 & & & \\
\end{tabular}


Varimax rotasyonlu temel bileşen analizinde, Tablo 4'te görüldüğü gibi 1. Faktörde $\mathrm{Cd}, \mathrm{Pb}$ ve $\mathrm{Zn}$; 2 . Faktörde $\mathrm{Cu}, \mathrm{Mn}$ ve $\mathrm{Ni}$; 3. Faktörde As değişkeni yer almaktadır. Faktör 1 doğal / jeolojik (Pb-Zn cevherleşmesi) ve antropojenik (eski maden kalıntıları veya atıkları), Faktör 2 doğal / litolojik kirlilik kaynakları ile ilgili olabilir. Faktör 3 olarak adlandırılan As grubu ise, kil mineralleri ile ilgili olabilir.

Faktör 1 olarak adlandırılan As-Ba grubu, bu elementlerin jeolojik ve antropojenik kirlilik kaynakları ile ilgilidir.

Tablo 4. Rotasyonlu Faktör Matris Değerleri

\begin{tabular}{lrrr} 
& Faktör 1 & Faktör 2 & Faktör 3 \\
\hline $\mathbf{A s}$ & -0.018 & 0.095 & 0.97 \\
$\mathbf{C d}$ & 0.906 & 0.11 & -0.182 \\
$\mathbf{C u}$ & -0.044 & 0.745 & 0.534 \\
$\mathbf{M n}$ & 0.496 & 0.65 & 0.073 \\
$\mathbf{N i}$ & -0.167 & 0.845 & -0.024 \\
$\mathbf{P b}$ & 0.919 & -0.118 & -0.053 \\
$\mathbf{Z n}$ & 0.805 & -0.028 & 0.148 \\
\hline
\end{tabular}

Matematiksel olarak hesaplandığında, rotasyonsuz faktör yüklerinin faktör dönüşüm matrisi ile çarpılmasıyla, rotasyonlu faktör yükleri elde edilmektedir (Tablo 5). Faktör yükleri grafiğinde, faktörler ile faktör yükleri yer almaktadır. Bu grafikteki değişkenler, faktörler ile ortak varyanslardır (Şekil 3).

Tablo 5. Faktör Dönüşüm Matris Değerleri

\begin{tabular}{lrrr} 
& Faktör 1 & Faktör 2 & Faktör 3 \\
\hline Değişkenler 1 & 0.993 & 0.113 & -0.029 \\
Değişkenler 2 & -0.078 & 0.829 & 0.554 \\
Değişkenler 3 & 0.087 & -0.548 & 0.832 \\
\hline
\end{tabular}

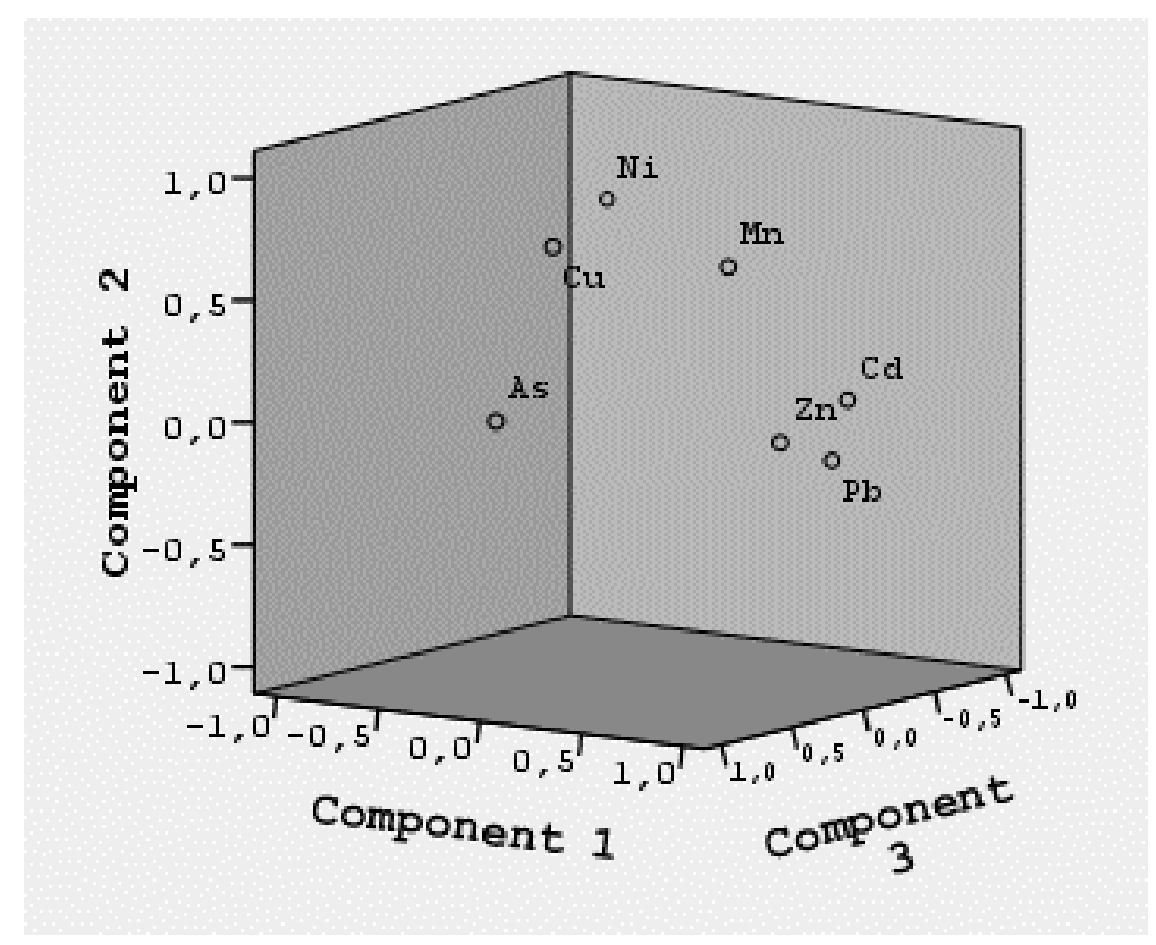

Şekil 3. Faktör Yükleri Grafiği 
Çalışma alanı ve çevresindeki dere sedimentlerinin alansal dağılımları Şekil 4'te verilmiştir. As ve Cu elementleri benzer bir alansal dağılım göstermektedir. Bu element değerleri 16 ve 17 nolu lokasyonlarda en yüksek değerlere sahip olduğu görülmüştür. Mn ve Ni elementleri çalışma alanında benzer bir dağılım göstermektedir. 3, 6 ve 7 nolu lokasyonlarda en yüksek element değerlerine sahiptir. Ayrıca, Mn değeri 1 ve 3 nolu lokasyonda da yüksek bir değere sahiptir. $\mathrm{Cd}, \mathrm{Pb}$ ve $\mathrm{Zn}$ element değerleri de benzer bir dağılım göstermiştir. $\mathrm{Cd}$ ve Pb elementleri çalışma alanınıon güneybatısında yani, 3 nolu loksayonda yüksek değere sahip olduğu gözlemiş̧tir. Ayrıca, $\mathrm{Pb}$ ve $\mathrm{Zn} 12$ nolu lokasyonda da yüksek element değerlerine sahiptir.
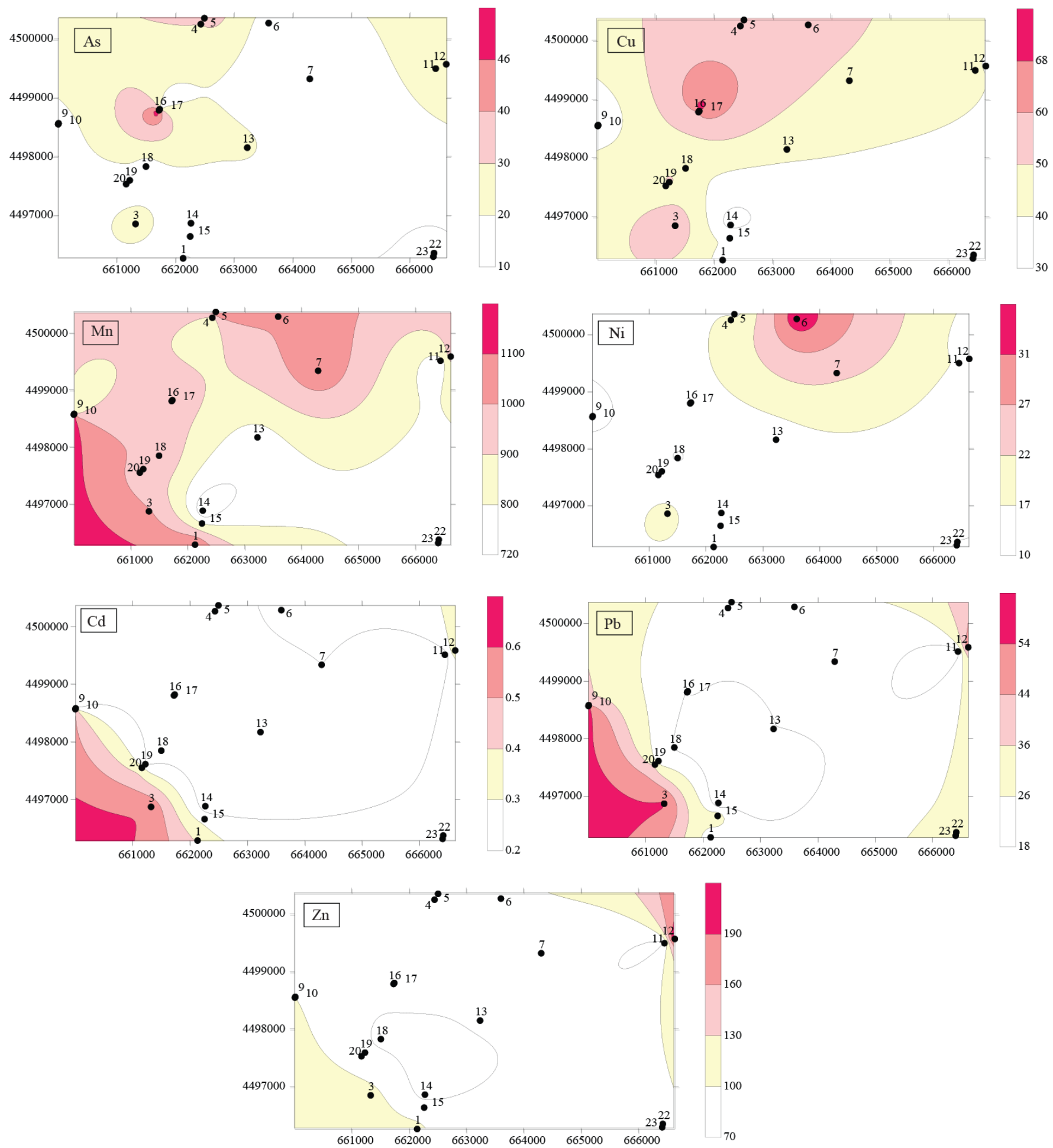

Şekil 4. Dere sedimentlerindeki elementlerin alansal dağılımı 


\section{Sonuç}

Balıkesir Merkez ilçesine $12 \mathrm{~km}$ uzaklıkta bulunan çalışma alanı ve çevresindeki dere sedimentleri magmatik, metamorfik ve volkanik kayaçlardan meydana gelmiştir. Çalışma alanı ve çevresinden farklı lokasyonlardan GPS yardımıyla 23 adet dere sediment örneği alınarak element içerikleri incelenmiştir. Dere sedimentlerindeki bu metallerin ortalama değerleri standart sapma değerlerinden yüksek olduğu görülmüştür. Spearman korelasyon katsayısı değerlerine göre, $\mathrm{As}-\mathrm{Cu}, \mathrm{Cd}-\mathrm{Pb}, \mathrm{Cd}-\mathrm{Zn}, \mathrm{Cu}-\mathrm{Ni}$ ve $\mathrm{Pb}-\mathrm{Zn}$ metal $(\mathrm{p}<0.01)$ birliktelikleri arasında yüksek pozitif korelasyon gözlenmiştir. Yapılan faktör analizleri ile 3 ayrı faktör değeri oluşturulmuştur. Faktör 1: $\mathrm{Cd}, \mathrm{Pb}, \mathrm{Zn}$ birlikteliği, Faktör 2: $\mathrm{Cu}, \mathrm{Mn}$, Ni birlikteliği ve Faktör 3: As ve Cu element birliktelikleri gözlenmiştir. Ayrıca incelenen metallerin dağılım haritaları oluşturularak metallerin alansal dağılımları incelenmiştir. As ile $\mathrm{Cu}$ elementleri $\mathrm{Mn}$ ile Ni ve $\mathrm{Cd}, \mathrm{Pb}$ ile $\mathrm{Zn}$ elementleri bazı lokasyonlarda çok yüksek değerlere sahip olmakla birlikte benzer bir dağılım göstermişlerdir.

\section{Katkı Belirtme}

GRC Madencilik Ltd. Şirketi bu çalışma sırasında desteklerini esirgemedikleri için teşekkür ederim.

\section{Referanslar}

[1] Ayodele, O, S. and Ogunniyi, S. O., "Geology and Stream Sediment Geochemical Survey of Okemesi Area", Southwestern Nigeria. Transnational Journal of Science and Technology, 2:73-97, 2011.

[2] Cannon, W. F., Woodruff L. G. and Pimley S., "Some statistical relationships between stream sediment and soil geochemistry in northwestern Wisconsin. Can stream sediment compositions be used to predict compositions of soils in glaciated terranes?" J. Geochem. Explor., 81: 29-46, 2004.

[3] Cohen, D. R., et al., "Comparison of vegetation and stream sediment geochemical patterns in northeastern New South Wales”. J. Geochem. Explor., 66: 469-489, 1999.

[4] Demirel, Z., Yıldırım, T., and Burçak, M., "Preliminary study on the occurrence of geothermal systems in the tectonic compressional regions: An example from the Derman geothermal field in the Biga Peninsula, Turkey" JAES, 22: $495-501$, 2004.

[5] Ercan, T., "Cenozoic volcanism in Central Anatolia". Journal Publication of Mineral Research and Exploration Rules.107:119-140, 1986.

[6] Grunsky, E. C., Drew, L. J. , David, M., and Sutphin, D. M., "Process recognition in multi-element soil and streamsediment geochemical data". Appl. Geochem., 24:1602-1616, 2009.

[7] Guagliardi., Apollaro, C., Scarciglia, F., and Rosa, R. D., "Influence of particle-size on geochemical distribution of stream sediments in the Lese river catchment, southern Italy”. Biotechnol. Agron. Soc. Environ. 17(1): 43-55, 2013.

[8] Krushensky, R. D., "Neogene calc-alkaline extrusive and intrusive rocks of the Karalar-Yesiller area, northwest Anatolia, Turkey" Bulletin of Volcanology,40:336-360, 1976.

[9] Lisowiec, N., Halley, S. H., and Ryan, L., "Using Deposit-scale Alteration and Geochemical Signatures to Explore for Analogue Deposits: a Case Study From the Mt Wright Gold Project”, Queensland Geochemical Case Histories \& Geochemical Exploration Methods. 969-972, 2007.

[10] Oyman, T., "Geochemistry, mineralogy and genesis of the Ayazmant Fe-Cu skarn deposit in Ayvalik, (Balikesir), Turkey” Ore Geology Reviews,37: 175-201, 2010.

[11] Polat, Y., "Faktör analizi yöntemlerinin karşılaştırmalı olarak incelenmesi ve hayvancılık denemesine uygulanışı". Çukurova Üniversitesi Fen Bilimleri Enstitüsü, Doktora Tezi, Zootekni Anabilim Dalı, 296 s., 2012.

[12] Pratt, C. and Lottermoser, B. G., "Mobilisation of traffic-derived trace metals from road corridors into coastal stream and estuarine sediments", Cairns, northern Australia. Environ. Geol., 52, 437-448, 2007.

[13] Ranasinghe, P. N., Chandrajith, R. L. R, Dissanayake, C. B. and Rupasinghe, M. S., "Importance of grain size factor in distribution of trace elements in stream sediments of Tropical High Grade Terrains". A case study from Sri Lanka. Chem. ErdeGeochem., 62, 243-253, 2002. 
[14] Ranasinghe, P. N., Fernando, G. W. A. R., Dissanayake, C. B. and Rupasinghe, M. S., "Stream sediment geochemistry of the Upper Mahaweli River Basin of Sri Lanka-Geological and environmental significance”. J. Geochem. Explor., 99, 1-28, 2008.

[15] Ranasinghe, P. N., et al., "Statistical evaluation of stream sediment geochemistry in interpreting the river catchment of high-grade metamorphic terrains". J. Geochem. Explor., 103, 97-114, 2009.

[16] Kirat, G., and Aydin, N., "Investigation of Metal Pollution in Moryayla (Erzurum) and Surrounding Stream Sediments, Turkey". International Journal of Environmental Science and Technology. Volume 15, Issue 10, pp 2229-2240. DOI: 10.1007/s13762-017-1611-9, 2018.

[17] Singh, P., "Geochemistry and provenance of stream sediments of the Ganga River and its major tributaries in the Himalayan region, India”. Chem. Geol., 269, 220-236, 2010.

[18] Taylor, B. E., "Epithermal gold deposits, in Goodfellow, WD, ed, Mineral Deposits of Canada: A Synthesis of Major Deposit-Types", District Metallogeny, the Evolution of Geological Provinces, and Exploration Methods: Geological Association of Canada, Mineral Deposits Division, Special Publication No.5, 113-139, 2007. 